\title{
BODY MASS INDEX, BLOOD PRESSURE AND SERUM CORTISOL LEVEL AS STRESS INDEX IN SYMPTOMATIC HIV/AIDS MALE SUBJECTS ON ANTIRETROVIRAL THERAPY NEGATIVE TO MALARIA PARASITE IN NNEWI, ANAMBRA STATE, NIGERIA
}

\author{
Ezeugwunne $\mathrm{IP}^{1}$, Ogbodo $\mathrm{EC}^{2}$, Analike $\mathrm{RA}^{3}$, Onuora $\mathrm{IJ}^{3}$, Obi-Ezeani $\mathrm{CN}^{4}, \mathrm{Ugwu}_{\mathrm{MC}}{ }^{2}$, Amah $\mathrm{UK}^{3}$, Okezie $\mathrm{AO}^{5}$, \\ Onyenkwe $\mathrm{CC}^{3}$, Ahaneku $\mathrm{JE}^{3}$
}

${ }^{1}$ Department of Human Biochemistry, Faculty of Basic Medical Sciences, Nnamdi Azikiwe University, Nnewi, Nigeria ${ }^{2}$ Department of Medical Laboratory Science, Faculty of Health Sciences, Nnamdi Azikiwe University, Nnewi, Nigeria ${ }^{3}$ Department of Chemical Pathology, Faculty of Medicine, Nnamdi Azikiwe University, Nnewi, Nigeria

${ }^{4}$ Department of Chemical Pathology, Chukwuemeka Odumegwu Ojukwu University, Awka, Nigeria.

${ }^{5}$ Department of Chemical Pathology, Federal Teaching Hospital, Abakaliki, Ebonyi State, Nigeria.

\begin{abstract}
Background: HIV infection is a risk factor for a variety of endocrine problems. Objectives: This study investigated the body mass index (BMI), Systolic blood pressure (SBP), Diastolic blood pressure (DBP) and serum cortisol level as stress factor/index symptomatic HIV/AIDS male subjects on ART who are negative to malaria parasite in Nnewi, Anambra State, Nigeria. Methods: A total of 274 adult male participants aged between 18 and 60 (42 \pm 13$)$ years were randomly recruited at the Voluntary Counseling and Testing (VCT) Centre in Nnamdi Azikiwe University Teaching Hospital and grouped based on WHO criteria for staging HIV into symptomatic HIV (stage 11) infected male participants on ART (A: n=69), Symptomatic HIV subjects not on ART (B: n= 69), Asymptomatic HIV positive subjects (C: $n=68)$ and HIV seronegative subjects $(D: n=68)$. Blood samples were collected from the participants for the determination of HIV status by immunochromatography and HIV confirmation by Western Blot. Enzyme-Linked Immunosorbent Assay (ELISA) was used to assay for cortisol level. Results: The results showed a significantly increased BMI and decreased mean serum cortisol level in HIV/AIDS seropositive participants on ART than in those, not on ART $(\mathrm{p}<0.05)$. Also, the BMI and mean serum cortisol level were significantly decreased and increased respectively in HIV/AIDS seropositive participants not on ART than in Asymptomatic HIV positive subjects and control respectively $(p<0.05)$. However, the mean SBP and DBP did not differ significantly between the groups studied ( $p>0.05)$. Conclusion: This study revealed a decreased stress index in HIV/AIDS subjects on ART with hypercortisolism and lower BMI in symptomatic HIV participants, not on ART.
\end{abstract}

Keywords: HIV; AIDS; Malaria uninfected male subjects; Cortisol; Blood pressure; Antiretroviral therapy.

\section{INTRODUCTION}

Human Immunodeficiency Virus (HIV) was identified as the causative agent of Acquired Immunodeficiency Syndrome in 1983 [1]. HIV infection is a risk factor for a variety of endocrine problems [2] and throughout the world, heterosexual transmission is still the most common route of spreading HIV-1 infection [3]. Regrettably, the HIV widespread lingers to be a load worldwide and offers grave public health glitches in emerging countries particularly in Nigeria [4-6].

In 2013, UNAIDS estimated that globally 35.3million people were living with HIV-1 in the world [7]. Similarly, Nigeria is estimated to have the second highest number of persons living with HIV/AIDS after South Africa $[8,9]$.

\begin{tabular}{ll} 
eISSN: $2395-0471$ \\
iSSN: $2521-0394$ \\
\hline
\end{tabular}

As HIV continues to survive and replicate within its human host, it eventually weakens the immune system of the host, leaving the infected individual susceptible to opportunistic infections and neoplasms which have been observed to have affected the endocrine system in patients with AIDS [10]. HIV infected persons have an increased risk of developing endocrine abnormalities and many HIV infected persons have been reported to have elevated basal cortisol levels [11]. However, a number of these abnormalities occur as a result of nonspecific endocrine responses to stress, infection and malnutrition [12].

The hypothalamic pituitary adrenal (HPA) axis and the systemic sympathetic/adrenomedullary system are the peripheral branches of the stress system, whose main function is to maintain basal and stress-related homeostasis [13]. Generally, viral infections such as HIV/ AIDS are physiologically stressful. Therefore, this study assessed the body mass index, blood pressure and serum cortisol levels as stress index in symptomatic HIV/ AIDS male subjects on antiretroviral therapy negative to

Correspondence: Dr. I.P. Ezeugwunne; Department of Human Biochemistry, Faculty of Basic Medical Sciences, Nnamdi Azikiwe University, Nnewi, Nigeria. E-mail: goodnessifeoma007@yahoo.com 
malaria parasite in Nnewi, Anambra State, Nigeria

Aim: The study designed to evaluate the serum hormonal levels in malaria uninfected symptomatic HIV (Stage II) male subjects on antiretroviral therapy in Nnewi, South Eastern Nigeria.

\section{MATERIALS AND METHODOLOGY}

Study design: This is a case-controlled study

Ethics approval: The subjects were given informed consent, while the study design was approved by the ethical committee.

Research place: Nnamdi Azikiwe University Teaching Hospital, Nnewi, Nigeria.

Sample size: A total of 274 adult male participants

Inclusion criteria: aged between 18 and $60(42 \pm 13)$ years were randomly recruited at the Voluntary Counseling and Testing (VCT) Centre in Nnamdi Azikiwe University Teaching Hospital (NAUTH), Nnewi, Nigeria.

Grouping: Based on World Health Organization (WHO) criteria for staging HIV, the participants were grouped as follows: symptomatic HIV (stage 11) infected male participants on ART $(\mathrm{n}=69)$. Lamivudine, 150 $\mathrm{mg}$ twice daily, Stavudine, 40mg twice daily and Nevirapine, $200 \mathrm{mg}$ twice daily: this was administered to the symptomatic HIV stage 11 subjects on ART. Symptomatic HIV subjects not on ART ( $\mathrm{n}=69)$, Asymptomatic HIV positive subjects $(\mathrm{n}=68)$ and HIV seronegative subjects $(n=68)$.

\section{Methodology:}

$5 \mathrm{ml}$ of blood sample were collected from each of the participant in the groups. The serum samples were stored at $-20^{\circ} \mathrm{C}$ until analyzed. The participants were screened for HIV infection using Immunoassay and Immunochromatographic method. The serum was used for the estimation of cortisol level.

Detection of antibodies to HIV-1 and HIV-2in human plasma: Two different methods were used, namely, Abbott determine TM HIV -1 and HIV-2 kit, which is an in-vitro visually read immunoassay (Abbott Japan Co.Ltd. Tokyo, Japan) and HIV-1 and 2 STAT-PAK Assay kit, which is an Immunochromatographic test for the quantitative detection of antibodies to HIV-1 and HIV-2 in Human plasma (CHEMBIO Diagnostic system, Inc, New York, USA). For the Abbott determine TM HIV -1 and HIV-2 kit, the procedure described by the manufacturer were used for the analysis. Also, for the Immunochromatographic method for HIV-1 and HIV-2, the procedure described by the manufacturer was used for the analysis.

Estimation of Cortisol: Serum Cortisol was estimated by Enzyme Linked Immunosorbent assay (ELISA) method as described by DRG Diagnostics [14].

Measurement of body mass index and blood pressure readings: Body mass index (BMI) was calculated by using the method as described by [15], whereas, the blood pressure readings were based on the method according to Paynter and Parkin, [16].

Statistical analysis: The data obtained was statistically analyzed using Statistical Package for Social Sciences (SPSS) version 16.0. One of way analysis of variance (ANOVA) and students' t-test were used to compare means. The results were expressed as mean $\pm \mathrm{SD}$ and confidence limits was chosen at 95\% ( $\mathrm{P}<0.05)$. $\mathrm{P}<0.05$ was considered statistically significant while $\mathrm{P}>0.05$ was insignificant.

\section{RESULTS}

The result of analysis of variance showed that the mean BMI $\left(\mathrm{Kg} / \mathrm{m}^{2}\right)$ and serum cortisol concentration were significantly different amongst the group $(\mathrm{F}=20.958$ and $22.39)$ respectively $(\mathrm{p}<0.05)$, whereas, the mean SBP $(\mathrm{mmHg})$ and DBP $(\mathrm{mmHg})$ did not differ significantly amongst the group ( $\mathrm{F}=1.774$ and 1.999) respectively $(\mathrm{p}>0.05)$.

The result of independent student's t-test showed that the mean BMI $(23.68 \pm 3.68 \mathrm{Vs} 19.61 \pm 3.40)$ as well as serum cortisol concentration (139.78 \pm 63.24 Vs $250.56 \pm 135.24)$ were significantly lower in HIV/AIDS seropositive participants on ART compared with HIV/ AIDS seropositive participants not on ART $(p=0.000)$ respectively, whereas the mean \pm SD of SBP and DBP did not differ significantly in HIV/AIDS participants on ART compared with values obtained in HIV/AIDS participants not on ART ( $p>0.05)$.

The mean \pm SD of BMI, SBP, DBP and serum cortisol level were similar in HIV/AIDS seropositive participants on ART in comparison with the values obtained in Asymptomatic HIV-positive subjects $(\mathrm{p}>0.05$ in each case).

Also, the mean \pm SD of BMI, SBP, DBP and serum cortisol level did not differ significantly in HIV/AIDS seropositive participants on ART than in the control group ( $p>0.05$ in each case).

However, the mean \pm SD of BMI in the HIV/AIDS seropositive participants not on ART was significantly lower compared with the values obtained in Asymptomatic HIV-positive subjects $(p=0.000)$, while the mean $\pm S D$ of serum cortisol concentration was significantly higher in HIV/AIDS seropositive participants not on ART than Asymptomatic HIV-positive subjects $(250.56 \pm 135.24$ Vs 141.81 $\pm 77.08 ; \mathrm{p}=0.000$ ).

Furthermore, the mean \pm SD of SBP and DBP were not significantly different in HIV/AIDS seropositive participants not on ART compared with Asymptomatic HIVpositive subjects ( $p>0.05$ in each case). Also, the mean \pm SD of BMI was significantly lower in the HIV/AIDS seropositive participants not on ART compared with control (19.61 \pm 3.40 Vs22.66 $\pm 3.10 ; p=0.000)$, whereas 
Table 1: Assessment of BMI, SBP, DBP and Serum cortisol in malaria negative HIV adult male subjects

\begin{tabular}{l|l|l|l|l}
\hline Variables & BMI $\left(\mathbf{K g} / \mathbf{m}^{2}\right)$ & SBP $(\mathbf{m m H g})$ & DBP $(\mathbf{m m H g})$ & Cortisol $(\mathbf{n g} / \mathbf{m l})$ \\
\hline HIV/AIDS on ART (A) & $23.68 \pm 3.63$ & $117.39 \pm 11.02$ & $73.55 \pm 7.02$ & $139.78 \pm 63.24$ \\
\hline HIV/AIDS not on ART (B) & $19.61 \pm 3.40$ & $119.71 \pm 13.50$ & $73.19 \pm 8.49$ & $250.56 \pm 135.24$ \\
\hline $\begin{array}{l}\text { Asymptomatic HIV positive sub- } \\
\text { ject (C) }\end{array}$ & $23.60 \pm 3.67$ & $112.35 \pm 12.35$ & $76.05 \pm 7.15$ & $141.81 \pm 77.08$ \\
\hline Control (D) & $22.66 \pm 3.10$ & $119.41 \pm 13.48$ & $77.79 \pm 9.28$ & $130.02 \pm 68.20$ \\
\hline P-value & 0.000 & 0.152 & 0.144 & 0.000 \\
\hline F-value & 20.958 & 1.774 & 1.999 & 22.39 \\
\hline A V B & 0.000 & 0.688 & 0.176 & 0.000 \\
\hline A V C & 0.999 & 0.069 & 1.000 & 0.488 \\
\hline A V D & 0.290 & 0.773 & 0.093 & 0.999 \\
\hline B V C & 0.000 & 0.631 & 0.152 & 0.000 \\
\hline B V D & 0.000 & 0.999 & 0.984 & 0.000 \\
\hline C V D & 0.374 & 0.544 & 0.246 & 0.936 \\
\hline
\end{tabular}

the mean \pm SD of serum cortisol level was significantly higher in HIV/AIDS seropositive participants not on ART than in the control $(250.56 \pm 135.24$ Vs $130.02 \pm 68.20 ; \mathrm{p}=0.000)$.

Again, the mean \pm SD of BMI, SBP, DBP and serum cortisol level in Asymptomatic HIV-positive subjects were similar with the values obtained in the control $(p>0.05$ in each case) respectively.

\section{DISCUSSION}

The introduction of anti-retroviral (AVR) drugs has significantly reduced both morbidity and mortality attributable to HIV infection [17].

The present study revealed a significant elevation in the mean body mass index (BMI) of HIV/AIDS seropositive participants on ART compared with HIV/AIDS seropositive subjects not on ART $(23.68 \pm 3.63$ Vs $19.61 \pm 3.40 ; \mathrm{p}=0.000$ ). This increase may be as a result of the beneficial and recovering potential of the antiretroviral therapy on the subjects used in this study. Again, it is suggestive of a reduction of wasting disease among the subjects on ART. Our finding is in line with the previous studies which had earlier documented varied degree of weight gain among HIV/AIDS subjects on ART [18-22]. However, based on the WHO classification of BMI levels given as follows [22]: underweight $\leq$ $18.5 \mathrm{~kg} / \mathrm{m}^{2}$, normal weight $=18.5-24.9 \mathrm{~kg} / \mathrm{m}^{2}$, overweight $=25.0-29.9 \mathrm{~kg} / \mathrm{m}^{2}$, obesity class $\mathrm{I}=30.0-34.9$ $\mathrm{kg} / \mathrm{m}^{2}$, obesity class II $=35.0-39.9 \mathrm{~kg} / \mathrm{m}^{2}$, obesity class III $\geq 40.0 \mathrm{~kg} / \mathrm{m}^{2}$, our participants on ART had an increased BMI which was still within the normal range $\left(18.5-24.9 \mathrm{~kg} / \mathrm{m}^{2}\right)$.

However, no significant statistical difference was observed in the present study between the mean body mass index of the HIV/AIDS seropositive participants on
ART compared with the control subjects ( $p>0.05$ ). This finding implies that the BMI of the HIV/AIDS seropositive subjects on ART are similar to that obtainable in the general healthy population; indicating an improving health status among the HIV/AIDS subjects on ART.

In this study, the mean Systolic blood pressure (SBP) and Diastolic blood pressure (DBP) did not differ significantly when compared between HIV/AIDS seropositive participants on ART and those not on ART $(\mathrm{P}>0.05)$. Similarly, no significant statistical differences were observed in the mean SBP and DBP of HIV/AIDS seropositive subjects on ART in comparison with the control group ( $>0.05$ ). This is in consonance with the report of Dimala et al. [23].

Interestingly, the mean cortisol level was significantly decreased in HIV/AIDS seropositive participants on ART than in HIV/AIDS seropositive participants not on ART (139.78 \pm 63.24 Vs $250.56 \pm 135.24 ; \mathrm{p}=0.000)$. This is in contrast with the report of Rateni et al. who reported similar levels of cortisol in HIV patients before and after ART [24]. This decrease may be attributed to the effect of ART on the adrenal gland. Also, it may imply an increased survival and reduced occurrence of opportunistic diseases after the use of ART [25], as viral infections are generally physiologically stressful.

Also, the mean cortisol level was observed to be significantly elevated in HIV/AIDS subjects not on ART than in control subjects $(\mathrm{p}=0.000)$. This finding is in keeping with the report of previous studies [26-28]. This confirms the fact that adrenal gland dysfunction is the most common and most serious endocrine disorder affecting HIV/AIDS patients [29]. Again, it is indicative of a high degree of stress experience by HIV/AIDS patients who are not receiving Anti-retroviral therapy. Furthermore, a number of pathogenic mechanisms have been postulated 
explaining the underlying mechanism behind the hypercortisolemia found in untreated HIV-positive persons. First, the shift of steroid metabolism from aldosterone, DHEA AND 17-deoxysteroids to cortisol may be indicative of an adaptive response to stress [30-33]. Secondly, it could be due to the cortisol binding globulin of HIV-infected patients that shows a higher number of binding sites compared with controls [34]. Again, the increased cortisol synthesis in the absence of an increase in corticotropin suggests that some non-pituitary factors derived from infected immune cell such as interleukin (IL) $-1 \beta$ and IL-6 $[27,35,36]$ might directly stimulate the adrenal cortex.

However, the mean cortisol level did not differ significantly between HIV/AIDS seropositive participants on ART and the controls ( $p=0.999)$. This may be suggestive of the ameliorative effect of ART on HIV/AIDS disease, thus reducing the stress level in the HIV/AIDS and restoring them similarly to that comparable with healthy population.

\section{CONCLUSION}

This study revealed a decreased stress index in HIV/ AIDS subjects on ART with hypercortisolism and lower BMI in symptomatic HIV participants not on ART. Also, the mean SBP and DBP of subjects remained same.

\section{Conflict of Interest: Declared none}

Funding: The study was not supported by any grant.

\section{REFERENCES}

[1] Finch RA, Moss P, Jeffries DJ, Anderson J. Infectious diseases, tropical medicine and sexually transmitted diseases. In: Kumar P, Clark M, eds. Clinical Medicine, London, Elsevier Saunders; 2005:19-152

[2] Hellerstein MK. Endocrine manifestations of HIV. HIV in-site. UCSF medical centre. 2013; Retrieved on July 2018. Available from http: hivinsite.ucsf.edu. (accessed on: 20 July, 2018 )

[3] Quinn TC. Global burden of the HIV pandemic. Lancet. 1996; 348:99-106

[4] Sule WF, Okonko IO, Yusuf OT, Donbraye E, Fadeyi A, Alli JA. HIV-1 and -2 Antibodies amongChildren in Anyigba, Kogi State, Nigeria. Asian Journalof Medical Sciences. 2010;2(4):1706

[5] Erhabor O, Ejele OA, Nwauche CA, Akani C, Cosmos E, Allagoa D, Edward-Alikor AD et al., Challenges Associated with the Effective Management of HIV Infection in a Low Income Setting in Sub-Saharan Africa: Case Study of Nigeria, HIVinfection - Impact, Awareness and Social Implications of living with HIV/AIDS. Available from: http://www.intechopen.com/books/hiv-infection- impact-awareness-and-social-implications-ofliving-with-hivaids/challenges-associatedwith-theeffective-management-of-hiv-infection-in-alowincome-setting-in-sub. accessed on: 20 July, 2018

[6] Tobin-West CI, Okeh CM. HIV/AIDS response in Rivers State, Nigeria: an evaluation of accomplishments and gaps. Port Harcourt Medical Journal. 2012;6(3):1

[7] Foley JF, Yu CR, Solow R, Yacobucci M, Peden, KWC, Farber JM. Roles for CXC chemokine ligands 10 and 11 in recruiting CD4+ T cells to HIV1 -infected monocyte-derived macrophages, dendritic cells, and lymph nodes. Journal of immunology (Baltimore). 2005;174:4892-900

[8] Sinha U, Sengupta N, Mukhopadhyay P, Roy KS. Humanimmunodeficiency virus endocrinopathy. Indian Journal of Endocrinology Metabolism. 2011;15:251-60

[9] Nigeria Federal Ministry of Health. National HIV and AIDS and Reproductive Health Survey 2012 (NARHS Plus II).

[10] Onyancha O, Ocholla D. Is HIV/AIDSin Africa Distinct? What Can We LearnFrom an Analysis of the Literature? Sciento metrics, 2009;79(1): 27796

[11] Ezeugwunne IP, Onyenekwe CC, Ifeanyichukwu M, Meludu SC, Chukwuanuku RC. Serum Fertility Hormonal Levels In Malaria Infected Symptomatic HIV Male Subjects in Nnewi, South Eastern Nigeria. IOSR Journal of Pharmacy and Biological Sciences. 2012;1(2):15-21

[12] Smith D. Endocrine complications in HIV progression. AIDS Treatment News, 1991: \# 140

[13] Chrousos GP. The hypothalamic-pituitaryadrenalaxis and immune-mediated inflammation. New England Journal of Medicine; 1995;332:1351 $-62$

[14] DRG Diagnostics. Cortisol ELIZA. In: cortisol ELISA user's manual. DRG instruments, Germany. $2006 ; 1-8$.

[15] Chobanian AV, Bakris GL, Black HR. Seventh Report of the Joint National Committee on Prevention, Detection, Evaluation and Treatment of High Blood Pressure. Hypertension. 2003;42(6): 1206-52

[16] Paynter AS., Parkin M. Growth in childhood. In: Stanfield P, Brueton M, eds. Diseases of Children in the Tropics and Subtropics: London: Hodder \& Stoughton. 1991;255-270.

[17] Palella FJ Jr, Delaney KM, Moorman AC. Declining morbidity and mortality among patients with 
advanced human immunodeficiency virus infection. New England Journal of Medicine.1998; 338:853-60

[18] Ferrando SJ, Rabkin JG, Lin SH, McElhiney M. Increase in body cellmass and decrease in wasting are associated with increasing potency ofantiretroviral therapy for HIV infection. AIDS Patient Care STDS. 2005;19: 216-23

[19] Luísa, HML, Ana BMMS. Metabolic abnormalities and over weight in HIV/AIDS persons-treated with antiretroviral therapy. Revistade Nutricao Campinas. 2008;21(3):277-283.

[20] Crum-Cianflone, N, Tejidor R., Medina S, Barahona I. Ganesan, A. Obesity among patients with HIV: the latest epidemic. AIDS Patient Care STDS. 2008;22: 925-30.

[21] Anyabolu EN. BMI and Risk Factors of Underweight andObesity in HIV Subjects in Eastern Nigeria.World Journal of AIDS. 2016;6:8-15.

[22] WHO. Physical Status: The Use and Interpretation of Anthropometry. Technical Report Series. World Health Organization, Geneva.1995;854, 1-1-9950

[23] Dimala CA, Atashili J, Mbuagbaw JC, Akam W, Monekosso GL. Prevalence of Hypertension in HIV/AIDS Patients on Highly Active Antiretroviral Therapy (HAART) Compared with HAARTNaïve Patients at the Limbe Regional Hospital, Cameroon. PLOS ONE. 2016; DOI:10.1371/ journal.pone. 0148100

[24] Rateni L, Lupo S, Racca L, Palazzi J, Ghersevich $\mathrm{S}$. Assessing endocrine and immune parameters in human immunodeficiency virus-infected patients before and after the immune reconstitution inflammatory syndrome. Archives of Endocrinology and Metabolism. 2018;62(1): 64-71

[25] Hendricks KM, Willis K, Houser R, Jones CY. Obesityin HIV-infection: dietary correlates. Journal of the American College of Nutrition.2006;25 (4):321-31

[26] Membreno L, Irony I, Dere W, Klein R, Biglieri EG, Cobb E. Adrenocortical function in acquired immunodeficiency syndrome. Journal of Endocrinology and Metabolism.1987;65:482-7

[27] Villette JM, Bourin P, Doinel C. Circadian variations in plasma levels of hypophyseal, adrenocortical and testicular hormones in men infected with human immunodeficiency virus. Journal of Endocrinology and Metabolism. 1990;70: 572-7

[28] Ibrahim ZU, Yahaya IA. Assessment of AdrenoCortical Function of Hiv/Aids Patients Using Salivary Cortisol. IOSR Journal of Dental and Medical Sciences. 2017;16(6Ver. VII):63-69
[29] Eledrisi MS, Verghese AC. Adrenal insufficiency in HIV infection: a review and recommendations. American Journal of Medical Sciences. 2001;32 (12):137-44

[30] Brown LS Jr, Singer F, Kilian P. Endocrine complications of AIDS and drug addiction. Endocrinology Metabolism Clinics of North America. 1991;20:655-73

[31] Grinspoon SK, Bilezikian, JP. HIV disease and the endocrine system. New England Journal of Medicine; 1992;327:1360-5

[32] Hofbauer LC, Heufelder AE. Endocrine implications of human immunodeficiency virus infection. Medicine (Baltimore). 1996;75: 262-78

[33] Lo JC, Schambelan M. Endocrine disease. In Dolin R, Masur H, Saag MS, eds. AIDS therapy. Philadelphia, pa: Churchill living stone;1999;74051

[34] Martin ME, Benassayag C, Amiel C, Canton P, Nunez EA. Alterations in the concentrations and binding properties of sex steroid-binding protein and corticosteroid-binding globulin in HIV positive patients. Journal Endocrinology investigation; 1992; 15:597-603

[35] Tauveron I, Thieblot P, Laurichesse, H. The cushing syndrome associated with AIDS. Annals of Internal Medicine. 1994;120: 620-1

[36] Biglino A, Limone P, Forno B. Altered adrenocorticotropin and cortisol response to corticotropin releasing hormone in HIV-1 infection. European Journal of Endocrinology. 1995;133:173-9. 